\title{
Study of normal and abnormal movements of mitral valve ring using reflected ultrasound
}

\author{
S. A. Chakorn, ${ }^{1}$ D. C. Siggers, C. F. P. Wharton, and D. C. Deuchar \\ From The Cardiac Department, Guy's Hospital, London
}

Reflected ultrasound has been used to show the relation of mitral valve ring to cusp movement in 5 normal subjects and in 43 patients with mitral valve disease. The effect of aortic regurgitation on the movements of the normal and the stenotic mitral valve have been studied in 8 patients.

It has been shown that the movement of the valve ring makes an important contribution to the apparent movement of the anterior cusp, especially when the ring movement is accentuated by the presence of aortic or mitral incompetence or when the cusp is more rigid in mitral valve disease and therefore moves very little relative to the ring.

The use of reflected ultrasound for studying the movement of intracardiac structures was first reported by Edler and Hertz (1954); their report showed that the movement of the anterior cusp of the mitral valve could be recorded by this method. Edler and Gustafson (1957) showed that the pattern of movement of the cusp is altered in mitral stenosis and their findings have been subsequently confirmed and expanded (Edler et al., 1961; Effert, 1963; Joyner, Reid, and Bond, 1963; Segal, Likoff, and Kingsley, 1966; Wharton, 1969; Wharton and Lopez Bescos, 1970).

The pattern of the movement of the StarrEdwards prosthetic valve inserted in the mitral position was first reported by Winters, Gimenez, and Soloff (1967); the recorded movement of the ball showed a resemblance to that of the natural valve in mitral stenosis. It has since been shown that this resemblance is because the ball remains in the apex of the cage throughout diastole and into early systole; the apparent movement of the ball recorded during this phase is due to movement of the cage with the valve ring; during systole the ball moves to the ring and remains in that position until diastole (Siggers, Srivongse, and Deuchar, 1971). This observation indicated the importance of knowing about the ring movement when interpreting the recorded movements of the ball or the natural valve cusp.

The movement of the mitral ring has been studied by Zaky, Grabhorn, and Feigenbaum

Received 6 July 197 .

${ }^{1}$ Present address: The Central Chest Hospital, Nondburi, Thailand.
(1967); they described in detail the normal movement of the ring and also made some observations on the movement in various heart diseases and observed in particular that the ratio of the amplitude of the movement of the ring during atrial contraction to the overall excursion of the ring during the complete cardiac cycle was altered in some forms of heart disease. The present study was undertaken to investigate further the movement of the mitral valve ring and the relation of its

FIG. I Normal ring and cusp movement.

The anterior cusp opens at point D. $C-D$

represents ring movement with the cusps in a closed position. $E-F$ is the combination of cusp closure and backward ring movement. $M V R=$ mitral valve ring.

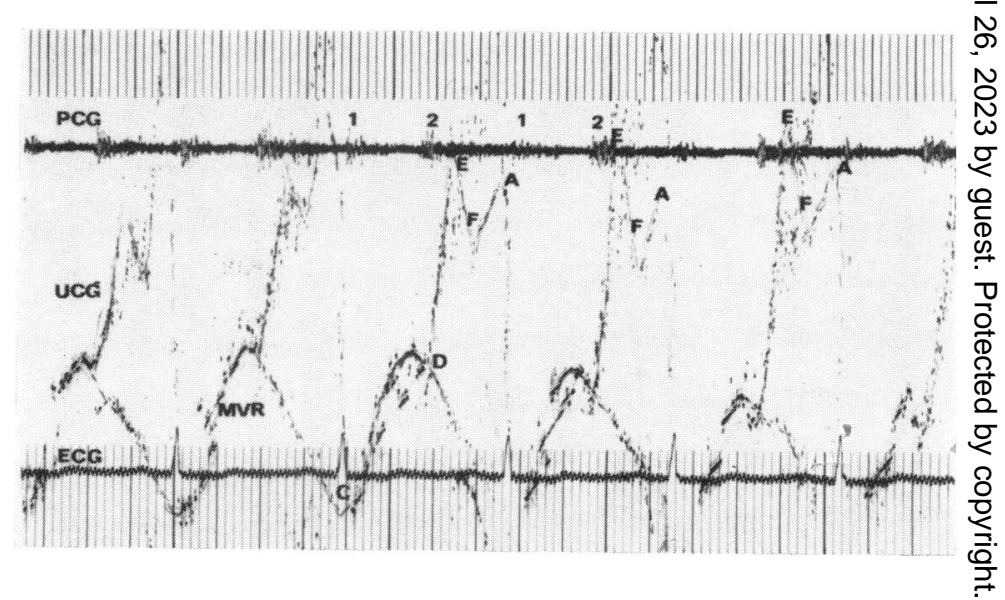


movement to that of the mitral valve anterior cusp in mitral and aortic valve disease.

\section{Subjects and methods}

$\rightarrow$ Records of the mitral ring movement were obtained from 5 normal subjects. The patients studied have been divided into two groups.

Group I: mitral valve disease (a) Mitral stenosis of varying degree ( 22 cases): 7 of these were studied before and after closed mitral valvotomy. (b) Mitral regurgitation, including

- examples of ruptured chordae tendineae found at operation (ro cases). (c) Mitral Starr-Edwards prosthetic valve (IO cases). (d) One case with a non-supported aortic homograft in the mitral

valve position.

Group II: aortic valve disease Aortic incompetence with a mid-diastolic murmur at the apex (8 cases). Three of these were found to have mitral stenosis at operation.

Wherever appropriate these patients were

- studied before and after operation or other relevant procedure.

The apparatus used in this study was the SmithKline Instrument Co., Eskoline 20 Diagnostic

Ultrasonoscope which transmits pulses of 2.5 megacycle ultrasound 1000 times a second. The transducer or ultrasound generating crystal was applied to the chest wall over the left praecordium

- at the points where maximum excursion of the ring and cusp are obtained on the record; this was

- not necessarily always the same place for both the ring and the cusp. The record of the movements of the ring and cusp was displayed on an oscilloscope and it was photographed by the Polaroid camera incorporated in the instrument; on these records calibration spots, representing $\mathrm{I} \mathrm{cm}$ deflection, are superimposed. In some cases the moving echo signal was transferred to a multi-

- channel recorder so that the movement of the ring could be recorded synchronously with the

. electrocardiogram and phonocardiogram. The Polaroid photographs of the modified ' $A$ ' scan wyere taken to show the best registration of the valve ring movement and as far as possible to show, in addition, the relation of the anterior cusp to the ring movement.

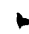

\section{Results}

Normal subjects In normal subjects the rapid anterior movement of the mitral cusp,

FIG. 2 The relation of ring and cusp move-

ment in (a) mild, (b) moderate, and (c) severe mitral stenosis. The $E-F$ slope diminishes with increasing severity of stenosis and cusp opening Secomes earlier in relation to the ring. In (c) cusp and ring echoes are fused to produce $a$ composite echo. The scale for the amplitude is the same in all these records.

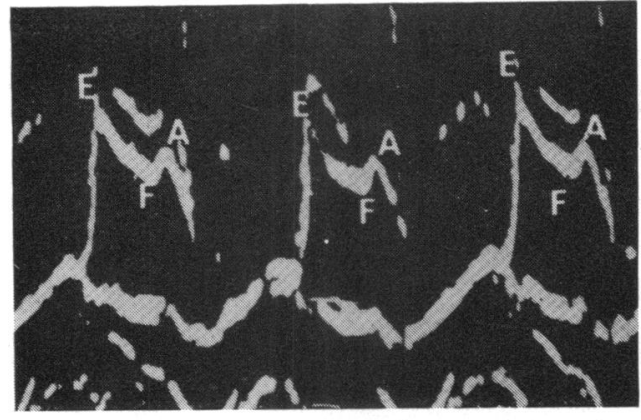

a

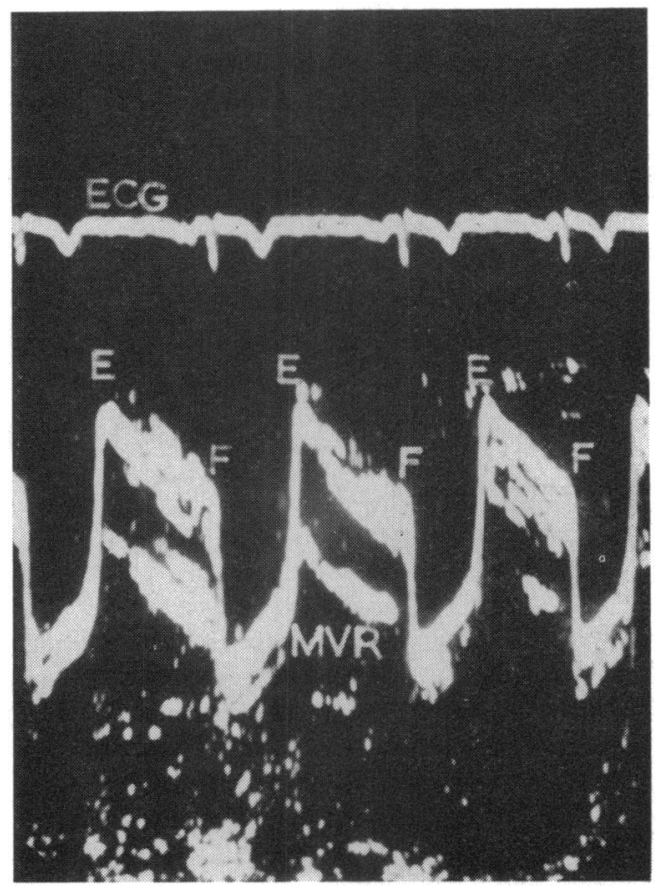

b

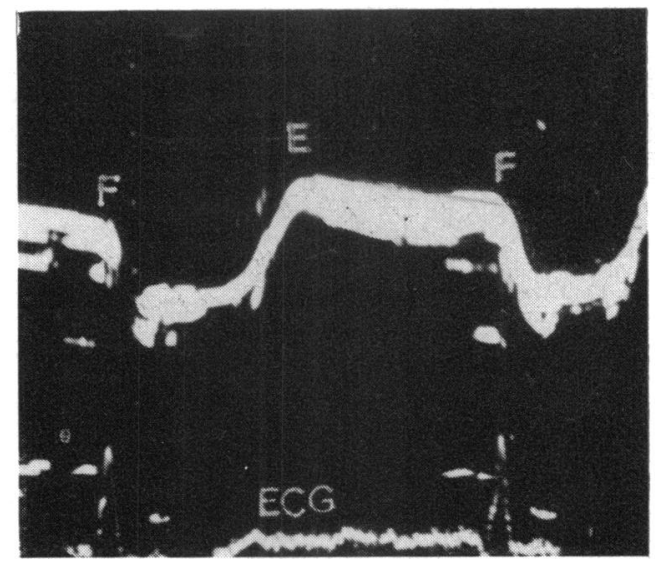




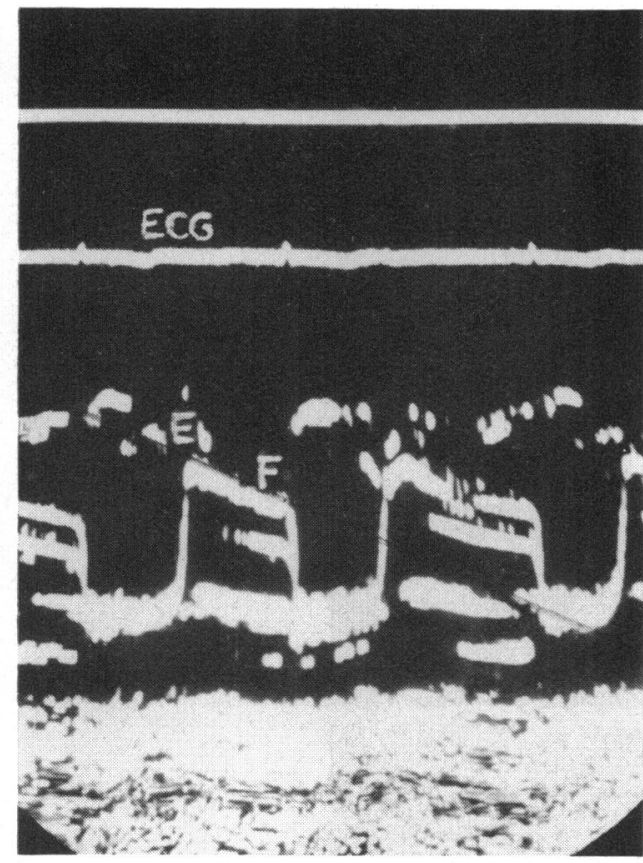

a

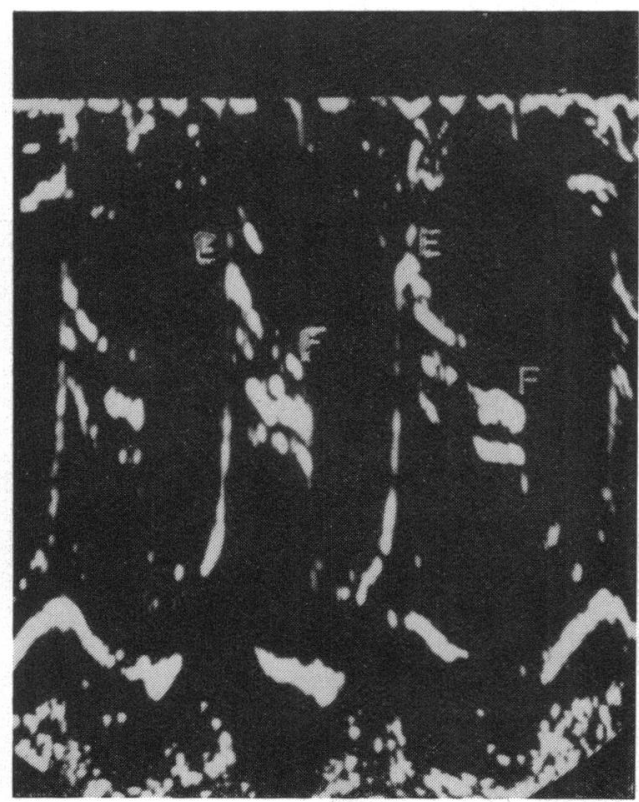

b

FIG. 3 (a) Mitral valve ring and cusp echoes before valvulotomy. In (b) after surgery the cusp movement is greater, ring excursion increased, and the cusp opening slightly earlier than the preoperative record. (Same scale for amplitude.)

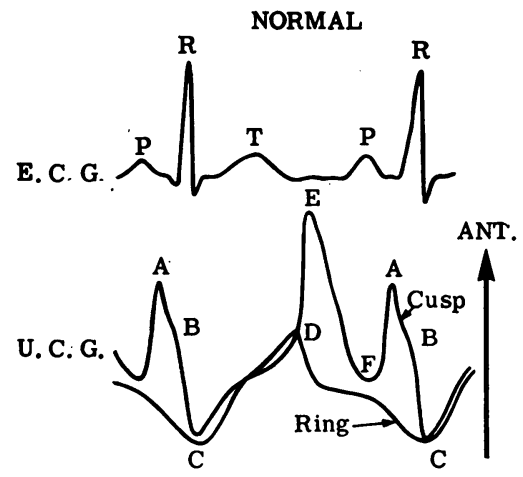

P. C. G.

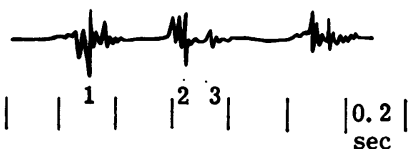

MITRAL STENOSIS WITH ATRIAL FIBRILLATION

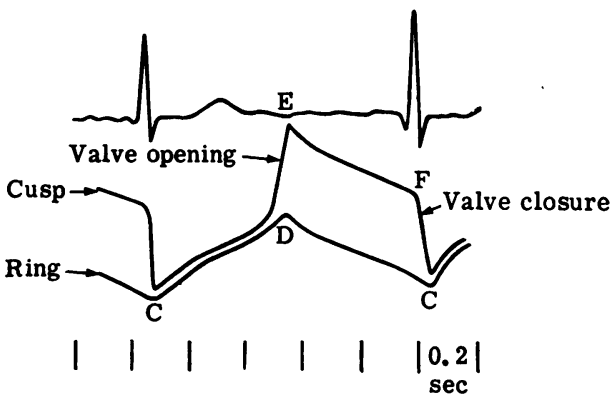

FIG. $4 A$ diagram to compare the relation between the ring and cusp movement in the normal subject with those in patients with mitral stenosis.

representing the opening of the valve, occurred at the same time as, or soon after, the maximum anterior movement of the ring. The cusps then returned posteriorly towards the closed position but reopened after atrial contraction. The mitral ring moved towards the apex at the beginning of systole and reached its most anterior position soon after the second sound; at this point the mitral cusps opened and then the ring gradually moved backwards during diastole. The anterior movement of the normal mitral cusp during systole is in fact due to the movement of the mitral ring together with the mitral cusps which remain in the closed position.

During diastole the mitral ring itself had three components of movement. In early diastole there was a rapid backward movement which corresponded to the rapid filling period of ventricular diastole; this was followed in mid-diastole by a gradual slow movement, almost forming a plateau on the 
record, during the slow filling period. The last component was a fast backward movement, associated with atrial contraction; this was always present in the normal subjects, but in cases with atrial fibrillation this component was absent.

The speed of the closing movement (the E-F slope) of the mitral cusp after rapid ventricular filling was faster than the simultaneous backward movement of the ring. The E-F slope was in fact a combination of the omovement of the cusp and the movement of the ring (Fig. I and 4).

Group I: mitral valve disease a) In mitral stenosis, with increasing severity of the lesion, the excursion of the anterior cusp from the ring was diminished; the opening amovement of the cusp (D-E slope) occurred earlier in relation to the maximum anterior movement of the ring than in normals (Fig. 2). After operation the mobility of the cusp was - increased and the cusp opened a little later, at the time of the maximum anterior movement of the ring (Fig. 3). Three cases showed a 'thick' echo record, representing fusion of 'ring and cusp, and they were found at operation to have heavily calcified valves. Fig. 4 is a drawing representing the different relation

- between mitral ring and cusp in normals and in mitral stenosis.

- b) In mitral incompetence (Fig. 5), part of the apparent increase in the excursion of the -valve cusp was due to increase in the amplitude of the ring movement. The normal relation of the cusp opening to the ring movement was maintained.

c) In the mitral Starr prosthesis (Fig. 6), the - ball moves to the 'open' position at the time of the maximal anterior movement of the cage.

- The ball remains in contact with the apex of the cage until the beginning of systole (Sigrgers et al., 1971).

d) Records were obtained from a patient with an inverted, unsupported aortic homograft valve in the mitral position who was also studied by left ventricular angiocardiography. The ultrasound recording of this valve suggested that the aortic homograft cusps moved - back, beyond the mitral valve ring, into the left atrium during systole, and that during diastole the cusps moved just through the ring into the left ventricle (Fig. 7); this pat-

tern of movement was confirmed by the cineangiocardiogram (Fig. 8).

Group II: aortic valve disease In pure aortic incompetence, without mitral valve involvement, the excursion of both the mitral ring and cusps was increased (Fig. 9). The

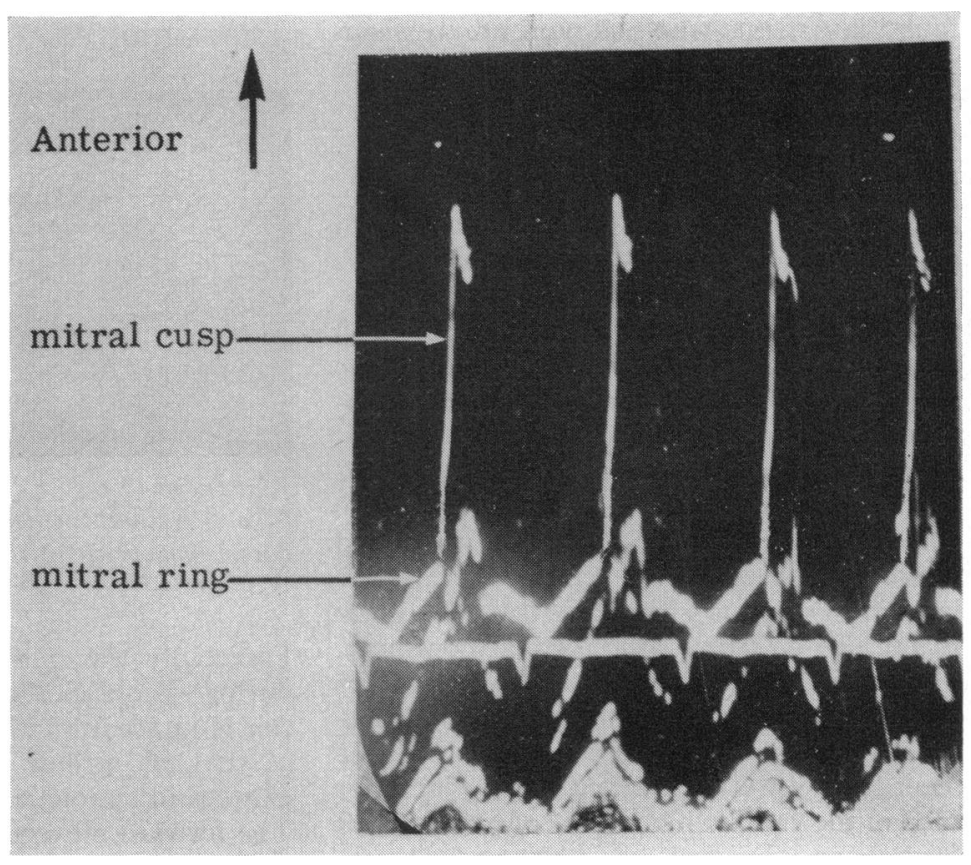

FIG. 5 Ring and cusp movement in mitral regurgitation. Cusp excursion is increased, this being partly due to an increase in ring movement. Ring and cusp relation is normal.

initial rate of closure of the cusps was faster than normal. The ring movement particularly was increased in patients with severe regurgitation.

In aortic incompetence with mitral stenosis the initial rate of closure was slower than normal and the excursion of the cusps was limited (Fig. 10). The excursion of both the ring and cusp was, however, greater than that

FIG. 6 Echoes from various components of the Starr-Edwards mitral prosthesis.

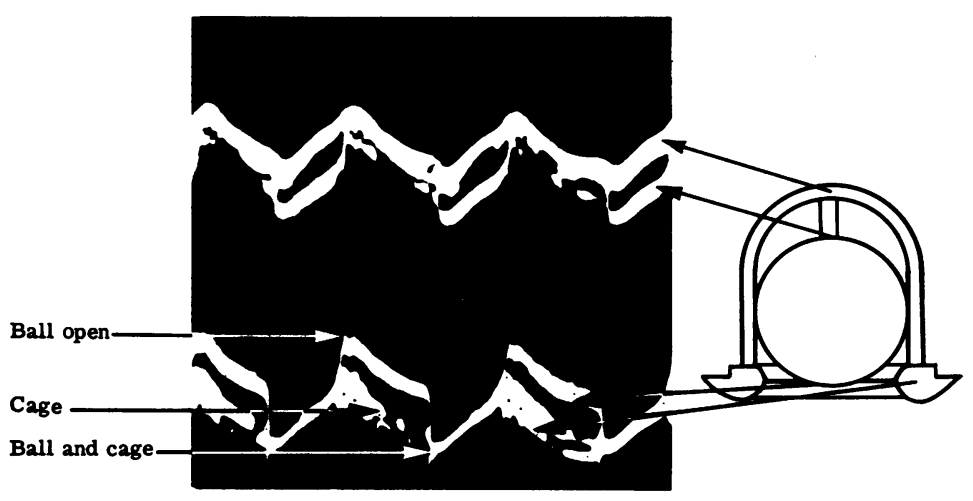


found in patients who had pure mitral stenosis found at operation to be of the same severity.

\section{Discussion}

A previous study of the ultrasound cardiogram of the mitral Starr-Edwards prosthetic valve (Siggers et al., I97I) showed clearly the relation between the movements of the ball and of the cage and showed that nearly all the apparent movement of the ball during the systolic and diastolic periods was due to movements of the cage, which is, of course, attached to the mitral valve ring. The close resemblance between the pattern of the ball movement and that of the anterior cusp of the natural valve in mitral stenosis suggested that the latter might also be largely due to ring movement.

It is clear from the present study that the excursion of the mitral valve ring is considerable and must contribute significantly to the recorded overall movement of the anterior cusp of the valve, which is, of course, attached to the ring. Our findings in the normal subjects agree with those of Zaky et al. (1967).

FIG. 7 The unsupported aortic homograft in a mitral position. The cusp is seen to move posteriorly into the left atrium during systole and moves just through the ring in diastole.

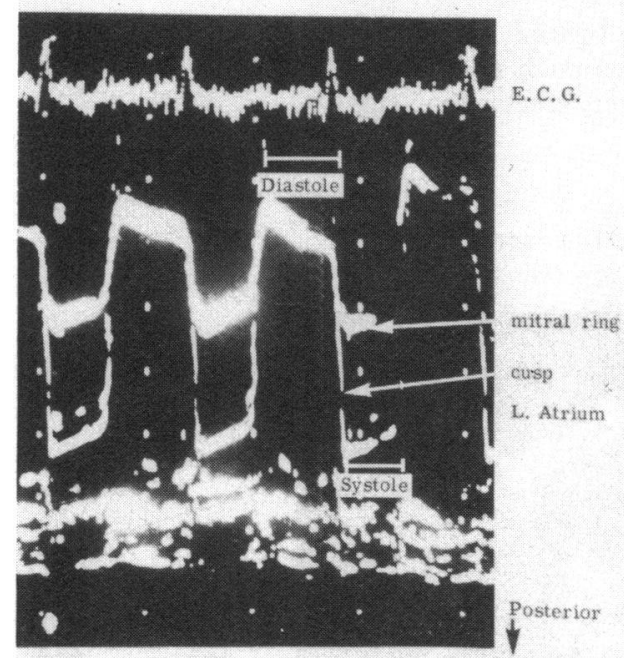

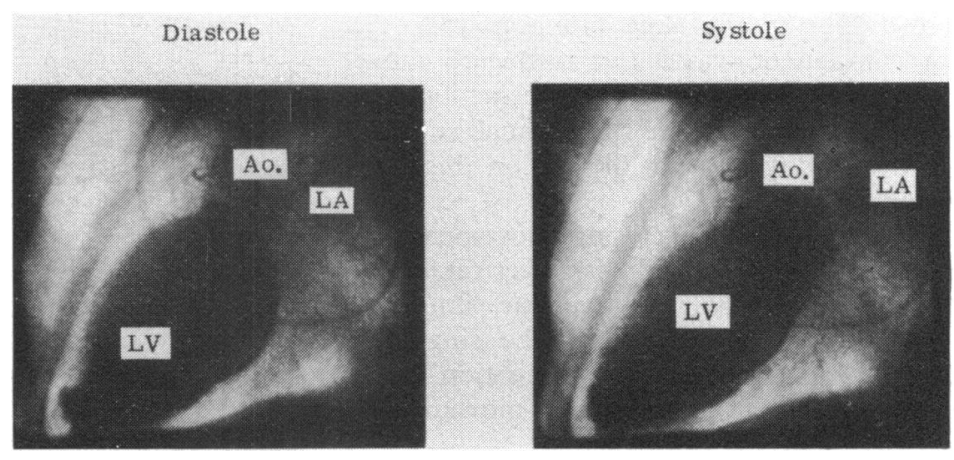

FIG. 8 Angiocardiogram of the unsupported aortic homograft in the mitral position.

Essentially the mitral ring moves forwards during systole and backwards during diastole; this is in accord with what one would expect as the left atrium fills while the ventricle empties in systole, and vice versa in diastole. The forward movement of the ring in systole accounts for the whole of the cusp movement during this time; this is only to be expected as the valve cusps are held in the fully closed position throughout systole. Sometimes at the end of systole the cusp appears to be further

FIG. 9 Mitral ring and cusp movement in aortic regurgitation. Excursion of each is increased. $M V R=$ mitral valve ring; $M V C=$ mitral valve cusp.

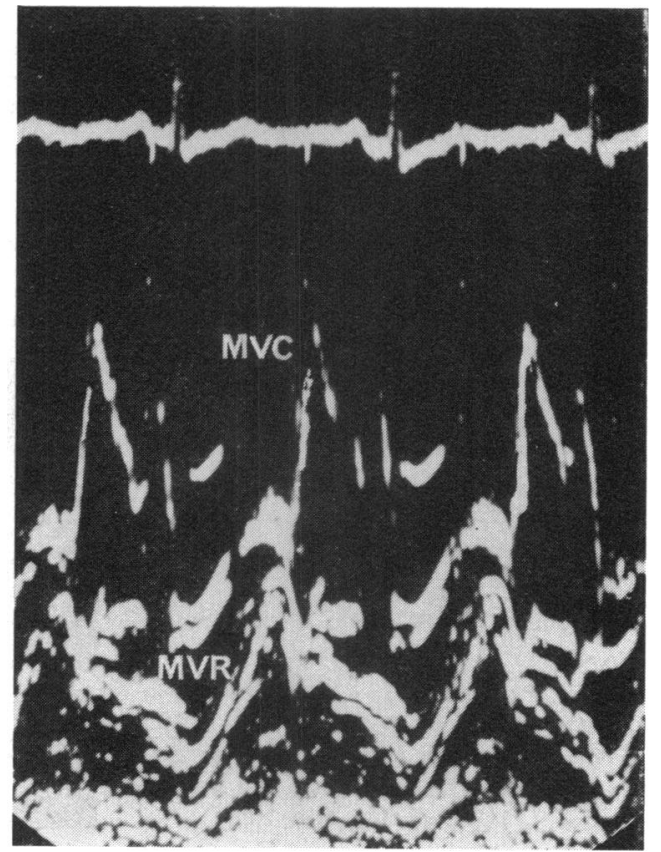




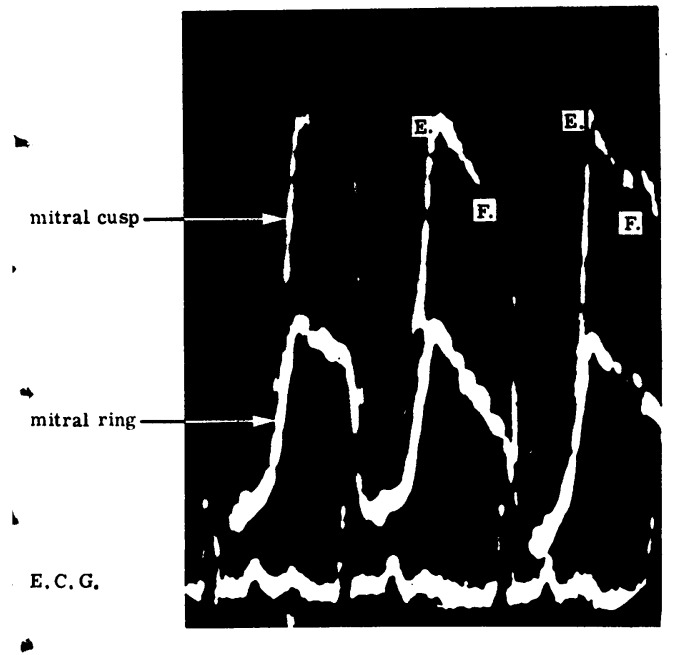

FIG. Io Relative mitral ring and cusp movement in mitral stenosis is not altered from the stenotic pattern by concomitant aortic regurgitation, though the total excursion is increased by greater ring movement

back than the ring; this could be accounted for by some ballooning of the cusps into the atrium as the left ventricle contracts and the

- papillary muscles move towards the valve ring. The three components of the backward

- movement in diastole, initial and terminal fast and an intermediate slow, correspond to the early rapid filling phase, the final extra ventricular filling during atrial systole, and the mid-diastolic period of diastasis, respectively.

It follows from this that valve lesions which ; result in increased left ventricular stroke volume are likely to be associated with in-

creased amplitude of movement of the mitral ring. This has been found to be so in the patients studied who had dominant mitral incompetence and those with aortic incompetence; the increased ring movement was - the most important factor contributing to the increased recorded overall excursion of the anterior cusp in these patients.

In contrast, in a patient with a non-supported aortic homograft in the mitral valve position, the ring movement was found to be normal whereas the cusp movement was found to be increased. This was confirmed by cineangiocardiography which showed the aortic cusp and the sleeve of the homograft prolapsing into the left atrium in systole producting a large excursion of the cusps.

In patients with mitral stenosis the situation is rather more complex. The amplitude of excursion of the ring is reduced in many patients, probably because of the reduced left ventricular stroke volume. Allowing for this, the excursion of the anterior cusp relative to the ring is also reduced because of the rigidity of the cusp and other parts of the valve mechanism. The diastolic portion of the record is of particular interest; the early diastolic, fast, backward movement of the ring becomes less apparent as the rapid filling of the ventricle is impeded by increasing degrees of mitral obstruction. With the onset of atrial fibrillation the terminal fast backward movement is also lost. The record of the diastolic backward movement of the ring in severe mitral stenosis with atrial fibrillation thus becomes a single low amplitude deflection. In the normal valve the cusp makes a rapid forward opening movement, which starts just after the ring reaches its most anterior position, and then moves back towards the closed position as the rapid filling ceases (the E-F slope); a late diastolic opening and closing movement occurs with atrial systole. During diastole the ring is moving backwards so that the E-F slope of the cusp movement represents a combination of ring movement and cusp-to-ring relative movement. With increasing mitral obstruction the onset of the opening movement of the cusp starts earlier: this accords with the earlier occurrence of the opening snap in more severe mitral stenosis and it is presumably affected by the same factors. The impeded and prolonged filling of the ventricle tends to hold the mitral cusp in the open position so that the backward closing movement of the normal cusp does not occur. With the onset of atrial fibrillation the movement of the cusp produced by atrial contraction also disappears, so that in severe mitral stenosis with atrial fibrillation the cusp once having moved to the open position at the beginning of diastole remains there until the next systole; the whole of the apparent movement of the cusp during diastole (the E-F slope) is now due to the ring movement. The situation is now exactly comparable to the movements of the ball and cage of the Starr-Edwards prosthesis.

In the movement record from the normal valve the E-F slope represents a closing movement of the valve after the early diastolic rapid filling of the ventricle. In some patients with severe mitral stenosis the excursion of the mitral valve (ring and cusp) was less than ro $\mathrm{mm}$, and these cases were found at operation to have distorted rigid valves which required replacement. It was in this group that the E-F slope represented the speed of movement of the ring alone and not the speed of closure of the anterior cusp. In these patients 
the cusps remain in the open position until the onset of systole; the rate of closure is then very fast as it is produced by the rapid pressure rise in the ventricle rather than by the vortex mechanism which probably closes the normal valve (Reid, I970). This may explain the accentuation of the first heart sound (mitral closing sound) in mitral stenosis.

\section{Conclusion}

The apparent movement of the anterior cusp of the mitral valve during systole as shown by the ultrasound cardiogram has been found to be due entirely to the ring movement in normal subjects.

The apparent increase in excursion of the mitral valve echo in mitral and aortic incompetence was found to be largely due to increases in ring movement.

With increasing degrees of mitral stenosis the apparent movement of the cusp (E-F slope) during diastole was increasingly accounted for by the ring movement.

The total excursion of the anterior cusp of the mitral valve as recorded by the ultrasound cardiogram in normal subjects and in patients with disease represents a combination of mitral valve ring movement (i.e. total valve movement) and relative movement of the cusp to the ring. Recognition of the contribution of the ring movements permits a better understanding of the cusp movement record.

We are grateful to the British Heart Foundation for a grant to one of us (C.F.P.W.) for the purchase of equipment used in this study.

\section{References}

Edler, I., and Gustafson, A. (1957). Ultrasonic cardiogram in mitral stenosis. Acta Medica Scandinavica, 159, 85 .
Edler, I., Gustafson, A., Karlefors, T., and Christensson, B. (1961). Ultrasound cardiography. Acta Medica Scandinavica, Suppl. 370.

Edler, I., and Hertz, C. H. (1954). The use of ultrasonic reflectoscope for the continuous recording of the movement of heart walls. Kungliga Fysiografiska Sällskapets $i$ Lund Förhandlingar, 24, 40.

Effert, S. (1963). Diagnostic value of ultrasonic cardiography. British fournal of Radiology, 36, 302.

Joyner, C. R., Reid, J. M., and Bond, J. P. (1963). Reflected ultrasound in the assessment of mitral valve disease. Circulation, 27, 503.

Reid, K. G. (1970). Design criteria for a prosthetic orthotopic heart and mitral valve. Guy's Hospital Reports, I19, 209.

Segal, B. L., Likoff, W., and Kingsley, B. (1966). Echocardiography: clinical application in mitral stenosis. Fournal of the American Medical Association, 195, 161.

Segal, B. L., Likoff, W., and Kingsley, B. (1967). Echocardiography. American fournal of Cardiology, 19, 42.

Siggers, D. C., Srivongse, S. A., and Deuchar, D. (197I) Analysis of dynamics of mitral StarrEdwards valve prosthesis using reflected ultrasound. British Heart fournal, 33, 401 .

Wharton, C. F. P. (1969). Reflected ultrasound patterns in mitral valve disease. Guy's Hospital Reports, 118, 187 .

Wharton, C. F. P., and Lopez Bescos, L. (1970). Mitral valve movement: a study using an ultrasound technique. British Heart fournal, 32, 344 .

Winters, W. L., Jr., Gimenez, J., and Soloff, L. A. (1967). Clinical application of ultrasound in the analysis of prosthetic ball valve function. American fournal of Cardiology, 19, 97.

Zaky, A., Grabhorn, L., and Feigenbaum, H. (1967). Movement of the mitral ring: a study in ultrasound cardiography. Cardiovascular Research, 1, I2I.

Requests for reprints to Dr. D. C. Deuchar, Cardiac Department, Guy's Hospital, London SEI 9RT. 